\title{
The Formation of Voting Behaviour Explained by Voting for Anti-European
}

\section{Parties}

Jim Pace Walker, University of Huddersfield

\section{¡impacewalker@gmail.com}

Accepted date: $24 / 11 / 17$

Published date: 21/02/2018

\section{Abstract}

The Brexit referendum and the last presidential election in the USA are just two examples of recent vote results that have been wrongly predicted. This research paper aims to identify the formation of voting behaviour to revaluate the necessary factors and variables in the correct and scientific prediction and analysis of voting behaviour. More specifically, this paper chose anti-European voting behaviour in Germany, which is also a current European-wide societal phenomenon, to analyse and explain the formation of general voting behaviour in detail. Many researchers, including Goodwin and Heath (2016), analysed the quality of existing polling methodology to explain the incorrect prediction of the Brexit result. This research forms a new approach towards the identification of voting behaviour by including more variables than usual. In collaboration with YouGov Deutschland GmbH, a strategic sample of the German population of 993 participants was formed. Participants were asked questions relating to individual differences, political ideology, attitudes towards daily political topics and socio-demographic factors. Voters who voted for the AfD, the main anti-European party in Germany, were more likely to be in some form of relationship, were more likely to be male, and over-represented the age group 40-49. Finally, voters voted for the AfD because the party engaged with political topics in a way that no other party did. This research is somewhat limited 
because the questionnaire focused on voters voting for the AfD. Furthermore, quantitative research can only identify and analyse individual human behaviour to a certain extent, whereas qualitative data, which this research lacks, can potentially help to identify voting behaviour. Relevant and important factors such as political ideology and individual differences, which are included here, but are usually not part of political research, must play a role in the future identification of voting behaviour.

\section{Keywords}

Polling research, voting, voting intention, personality scores, regression analysis, AfD, Federal German elections

\section{Ethics}

Ethical consent has been given by the School of Human and Health Sciences of the University of Huddersfield. The research was conducted in collaboration with YouGov Germany $\mathrm{GmbH}$, which adheres to the common legal requirements of research in Germany and to the requirements set out by the professional association of German market and social researchers (Berufsverband Markt- und Sozialforscher, 2017), the registered association of German market and social research institutes (Arbeitskreis Deutscher Markt- und Sozialforschungsinstitute e.V., 2017) and the German society for online research (Deutsche Gesellschaft für Online-Forschung e.V., 2017).

\section{Acknowledgements}

Bettina \& Peter Walker, Julie Walker, Dr Jamie Halsall, Peter Mannott. 


\section{Introduction}

The presidential election in the USA and the referendum over the United Kingdom's membership of the EU were arguably the most important political events in this decade so far, and were wrongly predicted by many polling companies. Why, after decades of political science and polling research and in times of 'Big Data' were the results of these two events so wrongly predicted?

To answer this question, and to shed new light on the formation of voting behaviour, this research aims to identify the formation of voting behaviour by focusing on the relatively new right-wing and anti-European German party AfD (Alternative für Deutschland). A new, unusual and far-reaching approach towards polling research is necessary in times of rising populism in the western world.

Contemporary researchers such as Goodwin and Heath (2016), who, for instance, analysed and criticised a total of 121 opinion polls that predicted the outcome of the referendum on the UK's membership of the EU, focus on the existing methodology of polling research.

However, this research takes a different approach towards the topic. By taking a step back and utilising a broader approach towards the initial formation process of voting behaviour, the researcher hopes to create a clearer picture of the formation of such behaviour. Other research focuses on the finer details of polling methodology and the improvement of polling, whereas this research identifies five different factor groups of variables that are assumed to be able to explain the formation of voting behaviour considering all impact-causing factors. Obviously, the list of factors that play a role in the decision-making process of voting is not exhaustive, and research can only 
describe and analyse the process to a certain extent. Nevertheless, all available variables have been included in the statistical analysis to identify the formation of voting behaviour, incorporating the largest possible number of factors. This research is therefore able to provide a more accurate answer as to why individuals vote in a certain way, taking into account more variables and factors than usual.

The five main groups of factors that are considered to identify the origin of individual voting behaviour are:

- Personal voting intention in upcoming federal elections and general attitude towards politics

- Usage of media

- Questions about current daily affairs in Germany

- Demographics

- Personality traits

The purpose of including so many variables, many of them obviously not directly affecting the decision-making process on the surface, is to gather a deeper understanding and to potentially identify secondary factors which might have a statistically significant importance within the process.

\section{Literature review}

The literature review establishes the current academic work conducted in polling research and assesses the concepts of both political opinion and political ideology, which is crucial to the analysis of the data.

\section{Political opinion - What is an individual and a public opinion?}

Distinguishing between individual political opinion and public opinion is very important in the context of this research. For example, individual political opinion is 
subject to many influential aspects, such as family background, social context, and personal and social calculus (Beck, Dalton, Greene, \& Huckfeldt, 2002). Murphy and Shleifer (2004) for example, define political opinion as a complex societal construction. Due to the broadness of the concept of political opinion, this research will engage only with the concept of political ideology, which is described below.

\section{Political ideology - the classical framework for classifying political opinion}

Political ideology, the deeper manifestation of an underlying political opinion and political understanding, which in established and contemporary research is often used as a classical framework for the deeper classification of political opinion, is a concept which is not clearly defined in the academic world. There are several potential definitions which can serve for research purposes. For example, the definitions outlined by Jost (2009) and Feldman and Johnston (2014) have been utilised as part of other research designs. According to the researchers, a political ideology can be attributed to an individual as well as to a group of people.

For the purposes of this research, the definition of Freeden will be adhered to.

Political ideology is a set of ideas, beliefs, opinions, that exhibit a recurring pattern, are held by significant groups, compete over providing and controlling plans for public policy, and do so with the aim of justifying, contesting or changing the social and political arrangements and processes of a political community. (Freeden, 2003, p. 32)

Often, political ideology is 'classified' on a numerical scale from left to right to explain different entities of political ideology and make the different forms of this concept comparable. Within this approach, the more left-wing ideology is associated with lower numbers on the scale, while right-wing ideologies are associated with higher numbers on the scale. In summary, political ideology is practically conceptualised 
within this research using the approach that 'classifies' or 'ranks' political ideology on a scale.

\section{What are the factors that influence the creation and the further ideological manifestation of an ideology?}

The core part of the literature review in preparation for this research was clearly to identify the factors that influence the creation and the further ideological manifestation of an opinion. It is obvious that the list of factors that play a role in the individual decision-making process is not exhaustive, and that the sum of factors that play a role in the formation of a political ideology varies from individual to individual. Nevertheless, the research found that one factor in the individual political decisionmaking process is personality. To utilise personality traits within this research, the 'Five-factor model of personality' (Mondak \& Halperin, 2008) is used.

Unlike many other contemporary pieces of political research, this research does not focus on a very special aspect of the formation of a political ideology, opinion research or political research. Instead, as previously stated, the focus lies on the 'greater picture', meaning that underlying, indirect factors which in sum are responsible for the manifestation of a political ideology, and therefore voting behaviour, are subject to a greater level of analysis than usual.

Therefore, in addition to personality traits as one group of impact-causing factors, four more groups of factors (which were briefly mentioned in the introduction of this research) are chosen to be analysed: demographic scores, voting intention in the upcoming federal elections, usage of media, and questions about current daily affairs in Germany. 


\section{Influences within the measurement or assessment of a political opinion}

\section{(political ideology)}

In addition to the usual issues surrounding social research, there are a few abnormalities within political research that must be considered when engaging with the matter. Noelle-Neumann \& Petersen (2005) are key writers in polling research, and they explain in detail how survey design, the political opinion of the researcher and the way political questions are asked influence the final outcome of the research questions.

The German AfD as main trigger or political representatives for anti-European behaviour

The last relevant point in the literature review is the 'Alternative für Deutschland' (AfD). The party can clearly be identified as an anti-European party (Alternative für Deutschland, 2016; Berbuir, Lewandowsky, \& Siri, 2015), to serve as a practical example of anti-European ideological party manifestation.

\section{Methodology}

This research was carried out in a purely quantitative way using a positivist approach. An ontologically objectivist analysis was conducted of data drawn from a panel survey which explored voting as a process occurring in interaction with many factors that needed to be identified. Data and research outcomes were gathered first, and the most influence-causing factors regarding voting were then outlined.

Between 3 February 2017 and 10 February 2017 an online survey was sent out to the entire online panel of YouGov Deutschland GmbH via email. A total of 993 participants within Germany were selected to form a sample representative of the entire population and were asked to complete the survey, which related to five core 
aspects outlined above. This sample was formed by utilising the subpopulation of the YouGov online panel.

The sample was representative of the German population and has been sampled by YouGov Deutschland GmbH to represent the public of Germany accordingly. The data was recorded in categorical and continuous variables, and most of the data was categorical (continuous variables are age, political self-ranking left/right, and the five personality scores, Openness, Extraversion, Agreeableness, Conscientiousness and Neuroticism). The questionnaire was strongly influenced by the political ideology of the AfD. Therefore, the regression models may be violated, as there were fewer questions relating to other political ideologies to compare the different electorates and their reactions to certain survey questions.

\section{Findings and analysis}

Most of the data is categorical; therefore, preliminary analysis only described frequencies of the variables in Table 1. As previously outlined, the survey is representative of the population of Germany, so preliminary analysis regarding the frequency of category variables is not required. Table 1 shows the mean, median and standard deviation of the relevant continuous variables of the survey. None of the scores of the continuous variables show unexpected outliers or abnormalities. Originally, 'Political self-ranking left/right' included the score '977' which coded the answer 'Don't know/not specified', therefore the data excluded these participants when calculating mean, range and standard deviation. 
Table 1

Continuous variables used in this research

\begin{tabular}{lllll}
\hline & N & Range & Mean & Std. \\
& & & & Deviation \\
\hline calculated age & 993 & 66 & 48.59 & 16.215 \\
big5_CP_Conscientiousness & 371 & 24 & 20.84 & 4.741 \\
big5_CP_Extraversion & 371 & 24 & 14.77 & 4.492 \\
big5_CP_Neuroticism & 371 & 24 & 13.58 & 4.710 \\
big5_CP_Openness & 371 & 24 & 19.13 & 3.818 \\
big5_CP_Agreeableness & 371 & 21 & 19.44 & 4.164 \\
Political self-ranking left/right* & 864 & 10 & 4.69 & 1.934 \\
Valid N (listwise) & 371 & & & \\
\hline *Note: 'Political self-ranking left/right' excluded participants who stated 'Don't know/not specified'
\end{tabular}

*Note: 'Political self-ranking left/right' excluded participants who stated 'Don't know/not specified'.

A preliminary analysis of the data shows that there are overarching differences between the general electorate and the AfD electorate. For example, specific demographic scores such as gender, marital status and age, which in this research are relevant in the underlying manifestation of a political ideology, differ markedly. 


\section{Figure 1}

\section{Age groups across the electorate}

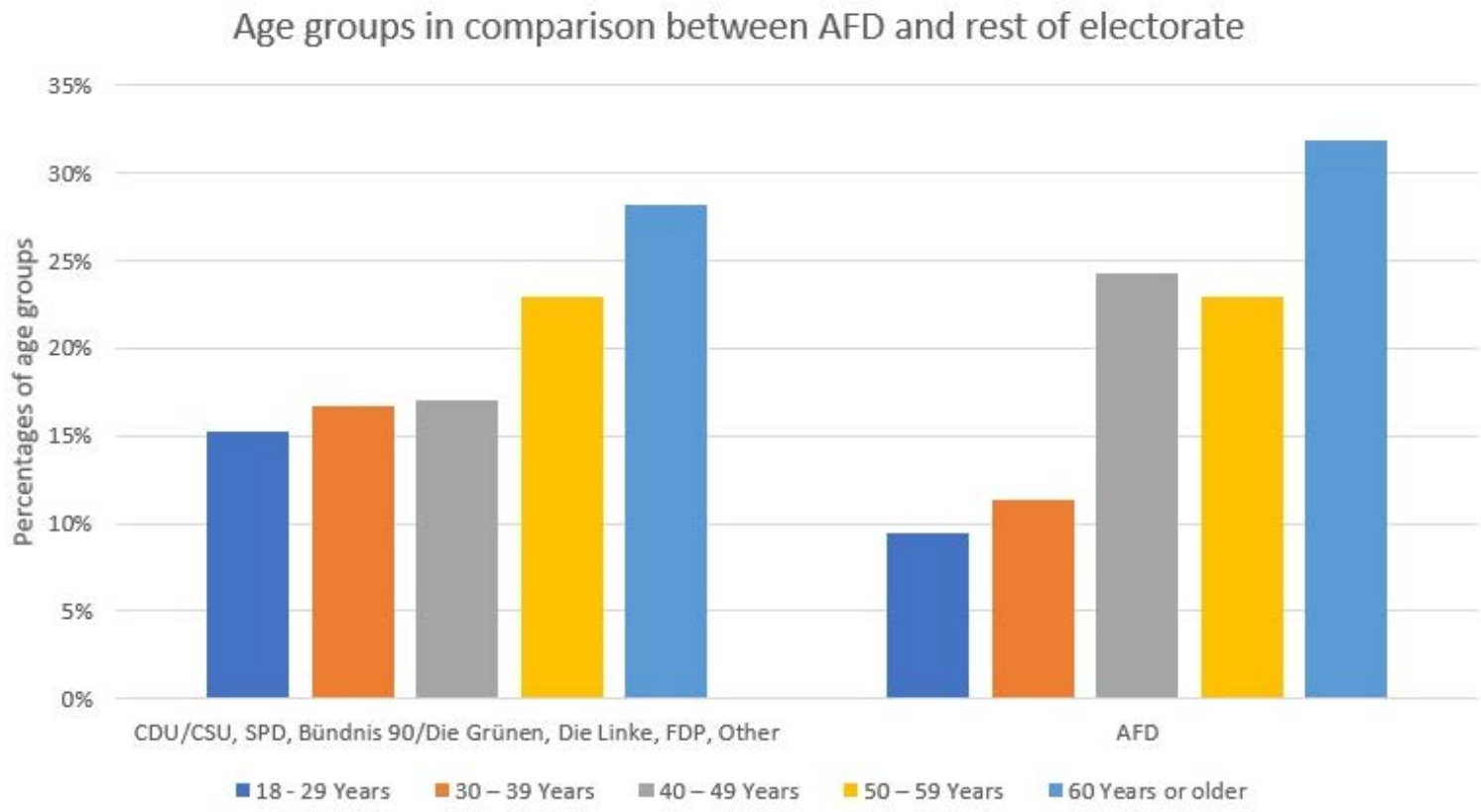

\section{Figure 2}

Gender in comparison between AfD and the rest of the electorate

\section{Gender}

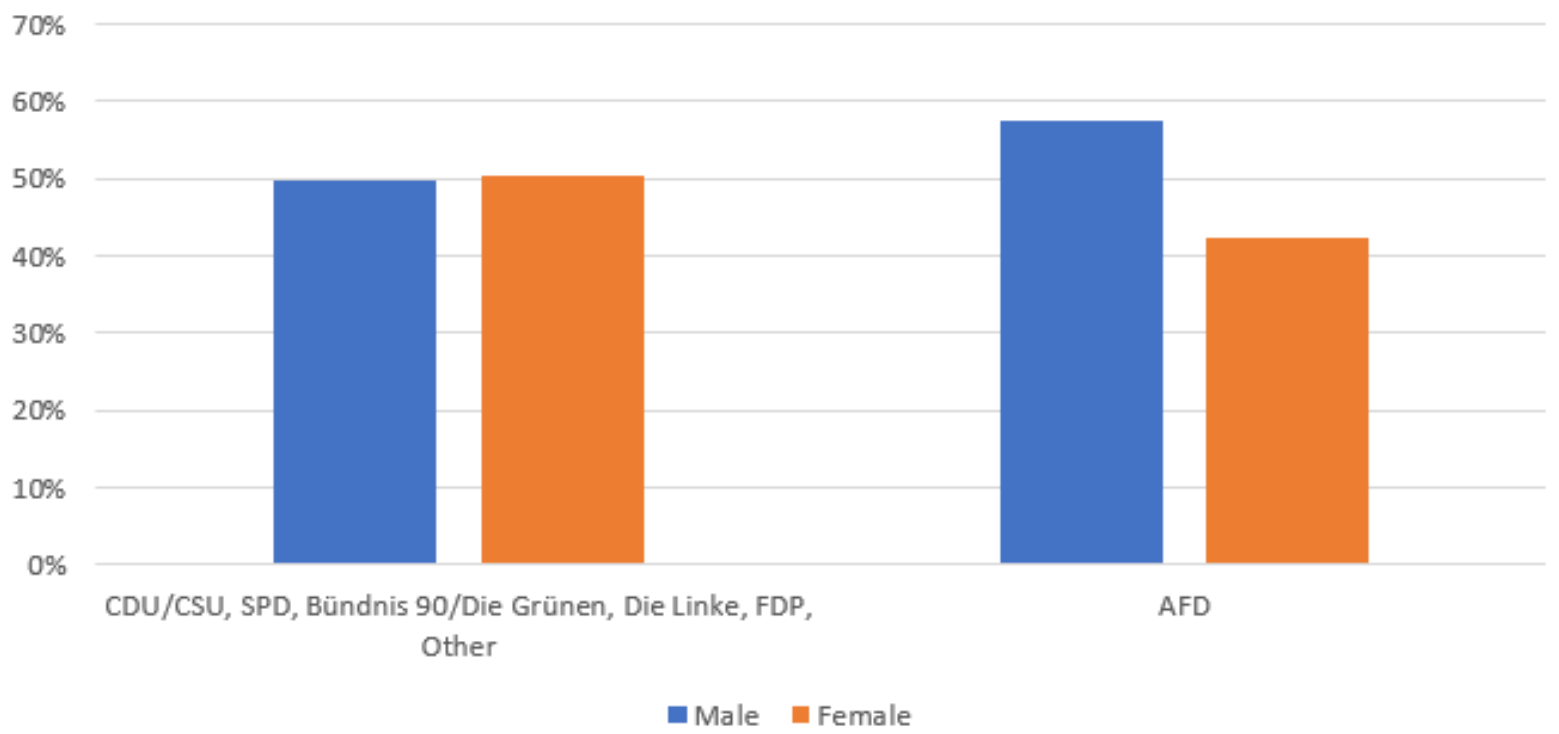




\section{Figure 3}

Marital status across the electorate

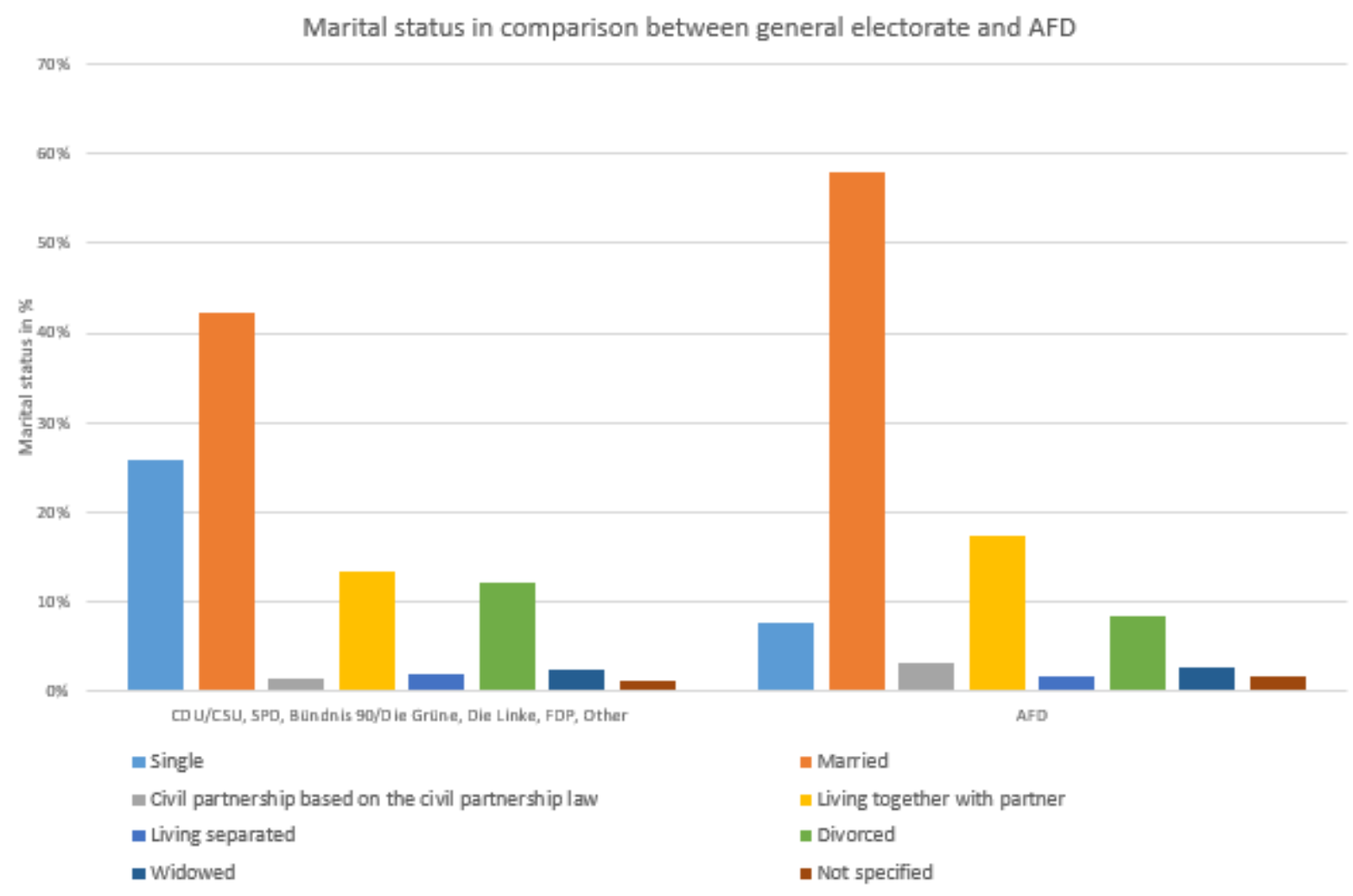

The comparisons in Figures 1-3 showed that AfD voters are more likely to be male than female, are over-represented in the age group 40-49 compared to any other major political party, and are more likely to be in some form of relationship than the general electorate, and less likely to be divorced.

Furthermore, two independent-samples $t$-tests were conducted to compare personality values between 'AfD' and 'Die Linke', and between 'CDU/CSU' and 'SPD'. There were significant differences in scores for Agreeableness between 'AfD' $(M=17.41, S D=4.59)$ and 'Die Linke' $(M=19.53, S D=4.58), t(81)=2.10, p=.041$, two-tailed.

There were significant differences in scores for Extraversion between 'AfD' (M = 14.35, SD = 4.54) and 'Die Linke' $(M=16.62, \mathrm{SD}=4.89), t(81)=2.20, p=.033$, twotailed, as well as for Openness between 'AfD' $(M=18.08, S D=4.10)$ and 'Die Linke' 
$(\mathrm{M}=19.97, \mathrm{SD}=3.40), t(81)=2.20, p=.030$, two-tailed. The magnitude of the differences in the means for Agreeableness and Extraversion were small (eta squared $=.050)$, for Openness it was medium (eta squared $=.060)$. The second independent sample $t$-test between 'CDU/CSU' and 'SPD' did not show any significant differences.

Binary regression models were conducted for each of the six analysed parties to identify if and to what extent political ideology (constructed using the variables 'long term party preference', 'political self-ranking left/right', 'political interest' and 'For which party did you cast your vote at the last federal election in 2013?') could determine voting behaviour. The positive predictive value (percentage of cases where the model could successfully determine voting in favour of AfD) of the binary regression model relating to the AfD was $82 \%$.

Role of the media, current daily topics, demographics and attitude towards politics and politicians in the formation of the voting process

With regard to the analysis of the demographic scores, a multinomial logistic regression was used to analyse more key variables and their predictive power for four groups of political voting behaviour. 'CDU/CSU' and 'SPD' combined were chosen as the reference category, as they mirror a large, centre-positioned part of the electorate. 'AfD' was chosen as the next category, followed by 'Sonstige', ‘Bündnis 90/Die Grüne', 'Die Linke' and 'FDP'. 'I would not vote' and 'Don’t know' was used as the fourth category. The variables that are mentioned in the first column of Table 1 show significance in the likelihood ratio test.

The full model containing all predictors was significant $\left(X^{2}(228)=921.47, p<.001\right)$, indicating that the model can distinguish between the four independent variables. 
The overall percentage of correctly classified cases was $66.4 \%$. In summary, this model could be utilised to predict voting behaviour.

There were significant differences which statistically categorised AfD voters, and therefore anti-European voting behaviour. Questions relating to Germany's membership of the EU and the euro currency itself showed strong significance. Participants who voted against Germany's membership of the EU and the euro as a currency were statistically more likely to vote for the AfD party. A regression model of this size arguably needed more participants to evaluate variables that do not directly relate to voting behaviour (e.g. main news source, marital status or educational attainment). However, according to Pallant (2013), the sample size is sufficient for this analysis, with $\mathrm{N}>50+8 \mathrm{~m}(\mathrm{~m}=$ number of independent variables), which resulted in sufficient sample size $(993>762)$.

This regression analysis was conducted to test whether a set of secondary variables could effectively determine differences in voting behaviour between parties. Again, the categorisation into four party groups was used and compared to the reference category (CDU/CSU and SPD). The AfD voters stated less political interest (OR = $0.13)$, higher use of printed newspapers $(O R=0.049)$, television $(O R=0.049)$ and radio $(O R=0.02)$ as their main news source. AfD voters agreed less with the statement that 'current immigration figures are just right' $(\mathrm{OR}=0.097)$. A highly significant factor was the statement 'the euro was good for Germany' (OR =0.015). It is important to mention that the euro is a key topic for the AfD as a Europe-criticising party, as outlined in the literature review (Alternative für Deutschland, 2016). 


\section{Anti-European voting behaviour - which factors determine voting in favour of}

AfD?

Lastly, a binary logistic regression was conducted to identify differences in voting behaviour between AfD voters and the general electorate. The full model with all predictors was statistically significant, $\mathrm{X}^{2}(73, \mathrm{~N}=920)=387.49, p<.001$, and stated that the model could distinguish between participants who would vote for AfD and participants who would not vote for AfD. The model explained between $34.4 \%$ (Cox \& Snell R squared) and 61.3\% (Nagelkerke R squared) of the variance in party preference for the AfD, and correctly predicted $73.6 \%$ of the cases.

The strongest positive predictors were 'school leaving qualification' and 'my personal environment votes the same way I do'. The strongest negative predictors were 'main news source' and 'political interest'. Overall, the variable category of questions related to daily affairs or societal affairs in Germany was shown to be the strongest group of predictors. The model deliberately excluded questions relating to political ideology, to identify whether secondary variables were also able to statistically detect anti-European voting behaviour.

In summary, the model could accurately predict $73.6 \%$ of the cases, and variables relating to daily affairs in Germany were the strongest subgroup of predictors. According to this model, not only was anti-European voting behaviour (voting in favour of AfD) strongly influenced by questions relating to daily affairs and personal voting environment, but main news source and reduced political interest were also relevant factors when it came to anti-European voting behaviour.

\section{Summary of findings}

This research evaluated and analysed the formation of voting behaviour on a stepby-step basis, beginning with innate psychological features, continuing with 
underlying political ideology, and concluded with the analysis of multivariate and bivariate analysis of a series of relevant variables. The anti-European electorate in general and the formation process of their voting behaviour have been researched in a statistically relevant way.

Both personality values and political ideology were shown to be the foundation of voting behaviour in this research. The personality values of the participants differed to a certain extent when it was tested for voting intention. Various political parties were compared, and are an increasing factor in the identification of different voting behaviour. Lower scores in Openness and Agreeableness did identify voters voting in favour of the AfD, which was in line with the findings of Schoen and Schumann (2007) and Samek (2017). Individual differences must play a part in future research that examines the formation of voting behaviour in more detail.

Political ideology, which in the context of this research could determine $74.5 \%$ of all cases correctly, is an undefined and broad concept with many academic definitions. Politicians, governments and researchers may therefore determine voting intention even before politically relevant topics or questions are presented to the participant. Further research must guarantee comparability, and an original and unique definition of political ideology must be established to guarantee and allow comparisons of further international research, as well as comparison of political ideology over time. As topical questions were directly aimed towards key topics of the AfD party programme, it was not sensible to include these questions in the identification of political ideology. Other concepts, such as 'Vote for Policies' (2017) and the 'Wahl-OMat' of the Bundeszentrale für politische Bildung (2017), ask the participant questions related to policies and calculate voting recommendations, but do not include the core questions regarding political ideology formed in this dissertation. Research must 
include these. A comparison of ideology based on the concept of ideology described in the literature review of this study and the formulated political ideology extracted from the answers of topical questions, political opinion and voting intention could aid towards the clarification of the formation of the voting process.

Both the multinomial and the binary regression models showed that questions related to daily affairs in Germany were by far the strongest predictors of voting behaviour when neglecting political ideology and personality values. Admittedly, the questions were relevant to the AfD electorate and further research must consider a neutral and more extensive catalogue of questions relating to daily topics in Germany.

Nevertheless, the regression model was statistically significant and able to determine $73.6 \%$ of cases when testing for non-AfD voters and AfD voters. This test showed that secondary predictors played a role in determining anti-European voting behaviour, and subsequent research must consider these predictors. For example, the final binary regression model in the analysis part of this study showed that 'my personal environment votes the same way I do' is one of the strongest predictors in this model, with 89 different predictors in total. Thus, anti-European voting behaviour in Germany is mainly caused by the positions taken by AfD relating to the topical questions outlined in this research. Furthermore, in the specific case of the antiEuropean party AfD, research has repeatedly stated that the AfD has no clear political general direction (Berbuir et al., 2015). The party mainly debates the topics that were tested for in this study (immigration, homosexuality, Islam, critique of Europe). Together with the so-called refugee crisis in 2015 , which saw the highest immigration numbers in Germany for decades, anti-European and right-wingorientated voters may have perceived the AfD as the only suitable political choice for their interests. The final binary regression model of the analysis proved this hypothesis. One general conclusion at this point is that anti-European voting 
behaviour in Germany mainly takes place because of these topical questions. Nevertheless, the formation of voting behaviour is a process constructed from many factors, and the output of regression models measured in percentages can never fully account for the decision-making process.

Underlying demographic differences between the AfD electorate and the general electorate were factors that also needed to be included in this study. While demographic variables were often recoded to fit the regression models to attain statistical significance, simple comparisons as shown in the introduction of the analysis part of this research showed that the AfD electorate consists of a different population. Some $60 \%$ of AfD voters were married, compared to $40 \%$ of the rest of the electorate. No party showed a bigger percentage of male voters (60\%), and the age group $40-49$ is overly represented (25\% compared to $15 \%$ on average for the other parties). Together with the evidence of the statistical analysis, the AfD electorate could be identified as predominantly male, married and aged between 40 and 49 years. Examining the intentions of this subgroup of male AfD voters aged 40 49 could also lead to an identification of the formation of voting behaviour in a more detailed way.

The very specific analysis of the demographic scores of the AfD can be used to understand the voters of the anti-European party in a better way, to shape political policies of all parties and to understand the concerns of the AfD electorate. Underlying sociological causes can be better explained using this far-reaching approach to the analysis of voting behaviour.

\section{Limitations}

This research has several limitations. The purely quantitative approach to the topic did not consider the potential outcome of qualitative research. As voting behaviour is 
an individual process based on human behaviour, the analysis of the process using numerical data was very complex. An additional qualitative question within the survey asking for the reason why participants would vote for their party could have provided more insight into the topic. This qualitative question could then have been recoded into categories of answers and included in the quantitative analysis. Furthermore, the regression models within the analysis section are relatively extensive, which could limit their predictive power.

\section{Further research}

This dissertation found voting behaviour in favour of anti-European parties to be caused by underlying political ideology, by innate personality values that differ from the general electorate, but mostly by certain and specific opinions of these voters regarding daily affairs and topics. Researchers and to a greater extent politicians have made the mistake of neglecting one or more of the predictor groups in their predictions of election results. This research has shown that is important to include all of them when aiming to explaining voting behaviour.

Future research must also guarantee and acknowledge the comparability of political ideology. Only by attaining a conceptual basis for political ideology can researchers compare this concept. A different definition than the one used in this dissertation could lead to different research outcomes. To gain more insight into the interaction of political ideology and opinion surrounding daily topical issues, this universally defined concept of political ideology should be included in research concepts such as Vote for Policies (2017). If questions relating to different affairs are used within research, it is important to balance them: this study, with its topical questions, only engaged with questions that were core topics of the AfD party. Furthermore, the comparability of 
using personality scores within political research must also be comparable to ensure that different political researchers can compare their findings.

The outcomes of past presidential elections in the USA and the referendum on the UK's membership of the EU were wrongly predicted by many polling companies and political institutes, and in the light of future national elections in Europe, a different approach to explaining anti-European voting behaviour must be taken. Two major insights could be gained by following this approach. Firstly, the right-wing methodology, their electorate and the formation of their voting behaviour could be better understood via further research. Secondly, politicians could use this enlarged and far-reaching method of explaining voting behaviour to understand the electorate prior to elections and to make informed decisions. The concept explained in this paper can be used not only by politicians and parties to win elections; the more important use could be to understand the constituency. By categorising the factors that play a role in the formation of voting behaviour, parties and politicians can statistically detect the most important factors and act accordingly. This would improve politics because politicians would focus on the most important topics first. 


\section{References}

Alternative für Deutschland, . (2017). Grundsatzprogramm der Alternative für Deutschland. In Bundesparteitag der AFD, Retrieved from https://www.afd.de/wp-content/uploads/sites/111/2017/01/2016-06-27_afdgrundsatzprogramm_web-version.pdf.

Arbeitskreis Deutscher Markt- und Sozialforschungsinstitute e.V., 2017. (2017). Richtlinie für die Veröffentlichung von Ergebnissen der Wahlforschung. Retrieved from https://www.adm-ev.de/richtlinien/

Beck, P.A., Dalton, R.J., Greene, S., \& Huckfeldt, R. (2002). The social calculus of voting: Interpersonal, media, and organizational influences on presidential choices. American Political Science Review, 96, 57-73.

doi:10.1017/S0003055402004239

Berbuir, N., Lewandowsky, M., \& Siri, J. (2015). The AfD and its sympathisers: Finally a right-wing populist movement in Germany? German Politics, 24, 154-178. doi:10.1080/09644008.2014.982546

Berufsverband Markt- und Sozialforscher. (2017). Icc/Esomar Internationaler Kodex für die Markt- und Sozialforschung. Retrieved from http://bvm.org/downloadbereich/

Bundeszentrale für politische Bildung. (2017). Wahl-O-Mat. Retrieved from http://www.bpb.de/politik/wahlen/wahl-o-mat/

Deutsche Gesellschaft für Online-Forschung e.V. (2017). Neue Schriften zur OnlineForschung. Retrieved from http://www.dgof.de/publikationen-2/neue-schriftenzur-online-forschung/ 
Feldman, S., \& Johnston, C. (2014). Understanding the determinants of political ideology: Implications of structural complexity. Political Psychology, 35, 337358. doi:10.1111/pops.12055

Freeden, M. (2003). Ideology. Oxford: Oxford University Press.

Goodwin, M.J., \& Heath, O. (2016). The 2016 referendum, Brexit and the left behind: An aggregate-level analysis of the result. The Political Quarterly, 87, 323-332. doi:10.1111/1467-923X.12285

Jost, J.T. (2009). 'Elective affinities': On the psychological bases of left-right differences. Psychological Inquiry, 20, 129-141. doi:10.1080/10478400903028599

Mondak, J.J., \& Halperin, K.D. (2008). A framework for the study of personality and political behaviour. British Journal of Political Science, 38, 335-362. doi:10.1017/S0007123408000173

Murphy, K.M., \& Shleifer, A. (2004). Persuasion in politics. The American Economic Review, 94, 435-439. doi:10.1257/0002828041301687

Noelle-Neumann, E., \& Petersen, T. (2005). Alle, nicht jeder: Einführung in Methoden der Demoskopie (4th ed.). Berlin: Springer.

Pallant, J. (2013). SPSS survival manual: A step by step guide to data analysis using IBM SPSS (5th ed.). Maidenhead: McGraw-Hill.

Samek, A.S. (2017). The association between personality traits and v oting in the 2016 US presidential election. CESR-Schaeffer Working Paper, 1 (2), 017. Retrieved from http://dx.doi.org/10.2139/ssrn.2910077. 
Schoen, H., \& Schumann, S. (2007). Personality traits, partisan attitudes, and voting behavior. Evidence from Germany. Political Psychology, 28, 471-498.

Vote for Policies. (2017). Retrieved from https://voteforpolicies.org.uk/ 